\title{
Quenching of acyl-homoserine lactone-dependent quorum sensing by enzymatic disruption of signal molecules
}

\author{
Robert Czajkowski ${ }^{1}$ and Sylwia Jafra ${ }^{\bowtie}$ \\ Laboratory of Plant Protection and Biotechnology, Department of Biotechnology, Intercollegiate Faculty \\ of Biotechnology, University of Gdansk and Medical University of Gdansk, Gdańsk, Poland
}

Received: 04 August, 2008; revised: 12 February, 2009; accepted: 15 February, 2009 available on-line: 17 February, 2009

\begin{abstract}
Many Gram-positive and Gram-negative bacteria communicate using small diffusible signal molecules called autoinducers. This process, known as quorum sensing (QS), links cell density to the expression of genes as diverse as those associated with virulence factors production of plant and animal pathogens, bioluminescence, antibiotic production, sporulation or biofilm formation. In Gram-negative bacteria, this communication is mainly mediated by $\mathrm{N}$-acyl-homoserine lactones (AHLs). It has been proven that inactivation of the signal molecules attenuates many of the processes controlled by QS. Enzymatic degradation of the signal molecules has been amply described. Two main classes of AHL-inactivating enzymes were identified: AHL lactonases which hydrolyse the lactone ring in AHLs, and AHL acylases (syn. AHL amidases) which liberate a free homoserine lactone and a fatty acid. Recently, AHL oxidoreductase, a novel type of AHL inactivating enzyme, was described. The activity of these enzymes results in silencing the QS-regulated processes, as degradation products cannot act as signal molecules. The ability to inactivate AHL (quo-

rum quenching, QQ) might be useful in controlling virulence of many pathogenic bacteria.
\end{abstract}

Keywords: quorum sensing, quorum quenching, acyl-homoserine lactones, AHL degradation

\section{OVERVIEW OF QUORUM SENSING MECHANISM}

Cell-to-cell communication is widely spread in bacteria and controls a broad range of activities (via modulation of gene expression) that result in bacterial phenotype changes and better adjustment to environmental conditions during growth (for review see: Swift et al., 1993; Kaiser \& Losick 1993; Fuqua et al., 2001; Whitehead et al., 2001; Podbielski \& Kreikemeyer, 2004; Reading \& Sperandino, 2006; Turovskiy et al., 2007). Quorum sensing (QS), the term introduced in 1994 by Fuqua et al. (1994), is an example of cell-to-cell communication and depends on the production, secretion and response to small, diffusible signal molecules also called autoinducers (Kaplan \& Greenberg, 1985). The signal molecules are produced and secreted during bacterial growth. Their concentration in the environment increases as the bacterial population expands, and when it reaches a threshold level (quorum level), it induces phenotypic effects by regulating QS-dependent target gene expression. Bacterial QS mechanism is based on two groups of signal molecules: peptide derivatives typical for Gram-positive bacteria, and fatty acid derivatives exploited by Gram-negative bacteria.

${ }^{\square}$ Corresponding author: Sylwia Jafra, Laboratory of Plant Protection and Biotechnology, Intercollegiate Faculty of Biotechnology, University of Gdansk and Medical University of Gdansk, Kładki 24, 80-822 Gdańsk, Poland; phone: (48) 58 523 6315; fax: (48) 58523 6426; e-mail: jafra@biotech.ug.gda.pl

${ }^{1}$ Present address: Plant Research International, P.O. Box 16, 6700 AA, Wageningen, The Netherlands; e-mail: robert.czajkowski@wur.nl

Abbreviations: acyl-ACP, acyl-acyl carrier protein; AHL, N-acyl-homoserine lactone; Blc, gamma-butyrolactone catabolism; C4-HSL, N-butanoyl-L-homoserine lactone; GBL, gamma-butyrolactone; GHB, gamma-hydroxybutyrate; 3-oxo-C6HSL, N-3-oxo-hexanoyl-L-homoserine lactone; 3-oxo-C8-HSL, N-3-oxo-ocatnoyl-L-homserine lactone; 3-oxo-C12-HSL, N-3oxo-dodecanoyl-L-homoserine lactone; QQ, quorum quenching; QS, quorum sensing; SA, succinate; SAM, S-adenosylmethionine; SSA, succinic semialdehyde. 
QS is omnipresent in many known bacteria species. It has been reported that most of bacteria, not only free-living in various environments but also those associated with higher organisms (symbionts or pathogens), use a sort of quorum sensing mechanism for controlling different 'social' activities.

Many human and plant pathogenic Gramnegative bacteria, including the genera Agrobacterium, Brucella, Bukholderia, Erwinia, Enterobacter, Pseudomonas, Ralstonia, Serratia, Vibrio and Yersinia (for review see: Fuqua \& Greenberg, 2002; Loh et al., 2002; Williams et al., 2007) utilize the QS mechanism for regulation of the virulence factors synthesis. Symbiotic bacteria of legumes belonging to the Rhizobium genus mediate their physiological processes connected with nodulation efficiency, symbiosome development as well as nitrogen fixation by means of complex regulatory systems based on signal molecules and QS (Rosemeyeer et al., 1998; Wisniewski-Dye et al., 2002; Marketon et al., 2002; Gonzalez \& Marketon, 2003; Hoang et al., 2004). This phenomenon was also observed in extremophilic microorganisms, such as the haloalkaliphilic archeon Natronococcus occultus (Paggi et al., 2003) or the acidophilic proteobacterium, Acidithiobacillus ferrooxidans (Farah et al., 2005; Rivas et al., 2007).

Gram-positive bacteria have developed cellto-cell communication as well. Bacteria from the genera Bacillus, Enterococcus, Staphylococcus, Streptococcus and Streptomyces exploit this mechanism to develop genetic competence, produce antimicrobial peptides or exotoxins and to form biofilm (Kleerebezem et al., 1997; Mayville et al., 1999; Claverys \& Havarstein, 2002; Knutsen et al., 2004; for review see: Podbielski \& Kreikemeyer, 2004).

Nowadays the QS mechanisms of Gram-positive and Gram-negative bacteria are being extensively studied as a new and promising target for reducing bacterial infections in humans, animals and plants.

In this review, we briefly overview the acylhomoserine lactone (AHL)-based QS mechanism of Gram-negative bacteria and focus on enzymatic degradation of AHLs resulting in silencing of the QS process, named quorum quenching.

\section{AHL-DEPENDENT QUORUM SENSING MECHANISM OF GRAM-NEGATIVE BACTERIA}

The best known and understood QS mechanism is the one described for Gram-negative bacteria. This mechanism involves production, secretion and response to the concentration changes of small signal molecules belonging to the $\mathrm{N}$-acyl-homoserine lactones (AHLs) family (Eberhard et al., 1981; Gray,

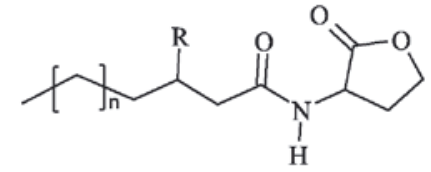

Figure 1. $N$-acyl homoserine lactone (AHL) - the main QS signal molecule of Gram-negative bacteria.

All AHLs are composed of the homoserine lactone ring and the acyl side chain that varies in length, oxidation state and presence of substituents. $\mathrm{R}$ - substituent at third carbon in the acyl side chain, hydrogen $(\mathrm{H})$, oxygen $(\mathrm{O})$ or the hydroxy group $(\mathrm{HO})$ in the known AHLs.

1997; Fuqua et al., 1994; 2001). The signal molecules of the AHL-type contain a homoserine lactone moiety and a fatty acyl side chain which, depending on the type of the signal molecule, varies in length, oxidation state and saturation level of the carbon chain (Fig. 1). For synthesis of AHL, S-adenosylmethionine (SAM) and acyl-acyl carrier protein (acyl-ACP) are required (Hanzelka \& Greeneberg, 1995).

An AHL-dependent QS mechanism was first described in the marine bacterium Vibrio fischeri (Photobacterium fischeri), where it is responsible for bioluminescence in a population density-dependent manner (Nealson et al., 1970; Eberhard, 1972; Kaplan \& Greenebrg, 1985). The paradigm of QS, at the molecular level, consists in the activity and cooperation of two components. The first is an AHL synthase (usually LuxI or LuxI homologue) which is responsible for constitutive synthesis of signal molecules (Fuqua \& Winans, 1996). The second one is a regulatory protein (LuxR and/or LuxR homologues) which promotes (in most cases) transcription of target genes, when bound with AHL (Fuqua et al., 1994). AHL binding requires three-dimensional changes of the regulatory protein and in turn allows its interactions with specific DNA regions enabling transcriptional activation of target genes (Fig. 2) (Hanzelka \& Greenberg, 1995). In most cases AHLs freely diffuse to the surrounding environment; however, AHL molecules with longer acyl side chains (over 10 carbons) are transferred from cells to the environment by an active or carrier-assisted transport system (Pearson et al., 1999).

Similar and homologous QS systems have been described in more than 70 different Gram-negative bacteria species (Bainton et al., 1992; Jones et al., 1993; Pirhonen et al., 1993; Zhang et al., 1993; Milton et al., 1997; Pearson et al., 1997; Cha et al., 1998; von Bodman et al., 2003; and more, for review see: Williams, 2007; Williams et al., 2007). The QS systems are responsible for controlling various activities, e.g. antibiotic production and resistance, conjugation, replication, virulence determinant production, exoenzyme synthesis, swarming, biofilm formation, bioluminescence and many others (Swift et al., 1993; 


\section{Low cell density}

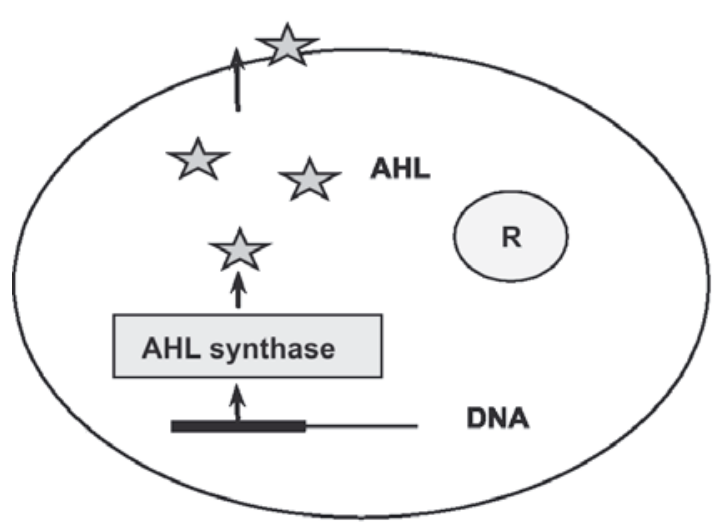

High cell density

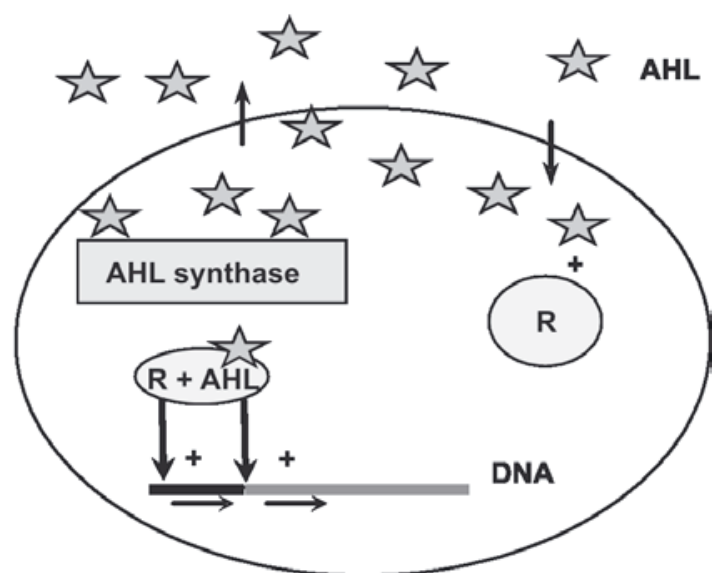

Figure 2. Overview of quorum sensing mechanism exploited by Gram-negative bacteria.

Bacterial cells produce signal molecules $-N$-acyl-homoserine lactones (AHLs) using specific enzyme - AHL synthase. The signal molecules are transferred into the environment and back to the cells by either passive diffusion or active ATP-dependent transport systems (low cell density). With an increasing density of bacterial population the AHLs accumulate in the environment and in the bacterial cells. When, the concentration of AHLs reaches a threshold level (quorum state), the signal molecules interact with the regulatory protein (R). The regulatory protein (R), in most cases, acts as a positive transcription regulator. The complex of $\mathrm{R}$ protein and AHL binds to promoters of target genes and initiates their expressions in a cell density-dependent manner (high cell density).

1996; Whitehead et al., 2001; Henke \& Bassler, 2004; Reading \& Sperandio, 2006).

Abundant AHL-dependent QS systems require a variety of signal molecules. Although various bacterial species produce the same type of AHLs, these molecules are responsible for the regulation of different processes, e.g. 3-oxo-C6-HSL is involved in exoenzyme and carbapanem production by Pectobacterium carotovorum (former: Erwinia carotovora), exopolysaccharide production of Pantoea (former Erwinia) stewartii and bioluminescence of $V$. fischeri (Eberhard et al., 1981; Bainton et al., 1992; Pirhonen et al., 1993; von Bodman \& Ferrand, 1995; von Bodman et al., 1998). Concurrently, bacteria of the same species produce distinct AHLs in strain-dependent manner. Such a phenomenon has been observed for various isolates of Rahnella aquatilis. One of the isolates from the tomato rhizosphere produces only 3-oxo-C6-HSL, whereas another one 3-oxo-C6-HSL and 3-oxo-C8-HSL (Steidle et al., 2001). A similar strain-dependent AHLs synthesis has been observed for different strains of $P$. carotovorum subsp. carotovorum (Chatterjee et al., 2005; Jafra et al., 2006a) and Burkholderia cepacia complex (Gotschilich et al., 2001).

Some QS systems are organized in a hierarchical way and control metabolism at more than one level. This phenomenon was detected in the human pathogen Pseudomonas aeruginosa (de Kievit \& Iglewski, 2000; Diggle et al., 2002) and the marine bacterium Vibrio anguillarum (Milton et al., 1997; 2001). In $P$. aeruginosa two distinct types of signal molecules (the long side-chain signal molecule 3oxo-C12-HSL and the short side-chain one C4-HSL) are involved in regulation of pathogenicity determinants, such as elastase and protease synthesis or swarming motility (de Kievit \& Iglewski, 2000). The synthesis of the short side-chain molecules is dependent on the QS mechanism mediated by the long side-chain one. Such a double QS system assures that targeted genes would be expressed only under very specific environmental conditions and at an appropriate threshold density of bacterial populations. However, detailed studies concerning regulation of synthesis of pathogenicity factors in $P$. aeruginosa cells have revealed that AHL-mediated QS is not the sole mechanism involved in this regulation and the regulation of expression of pathogenicity determinants is more complex (Reimmann et al., 1997; de Kievit \& Iglewski, 2000; Diggle et al., 2003).

During the last decade the number of publications concerning the QS mechanism in the bacterial world has been growing rapidly and it is next to impossible to present the complete data here. Instead, our review focusses on presenting only the current state of knowledge concerning quorum quenching (QQ) mechanism of Gram-negative bacteria. For further readings we strongly recommend following the original experimental work carried out on the subject.

\section{INTERFERENCE IN QS}

As the QS mechanism, among others, controls virulence factor synthesis in many pathogen- 
ic bacteria, it is now generally accepted that the ability to inactivate autoinducers and suppress QS signal generation and/or response might be useful in controlling infection development and persistence of human, animal and plant bacterial pathogens (Mäe et al., 2001; Fray, 2002; Hentzer et al., 2003; Zhang, 2003; Ozer et al., 2005).

Interference in the QS mechanism can be achieved in a variety of ways. First, many natural substances can disturb the signal perception by imitating AHLs structure. The AHL analogues block the AHL receptor (regulator) protein and therefore prevent activation of the target gene expression (Manefield et al., 1999). Halogenated furanones produced by red alga Delisea pulchra were able to inhibit AHL-dependent carbapenem antibiotic synthesis and extracellular plant cell wall degrading enzyme production in $P$. carotovorum subsp. carotovorum (Manefield et al., 2001).

Many studies showed that also higher plants produce and secrete secondary metabolites that interfere with the microbial QS systems (Teplitski et al., 2000; Gao et al., 2003). During the plant development, different compound that mimic bacterial signal molecules are secreted through the plant root system affecting significantly the rhizosphere bacterial gene expression (Gao et al., 2003). Those active plants compound have not been identified yet, so the mechanism of their interference with bacterial QS remians unknown. Recently, Adonizio et al. (2008) reported an inhibitory effect of aqueous extracts of plants Conocarpus erectus, Callistemon viminalis and Bucida buceras, on P. aeruginosa QS resulting in the inhibition of virulence factor production. Also here, the mode of action of active compounds is not known, however, their bacteriocidal or bacteriostatic activity has been excluded.

The growing potential of synthetic QS inhibitors is well-documented, too (Reverchon et al., 2002; Wu et al., 2004; Rasmussen et al., 2005; Muh et al., 2006). Synthetic analogues of $\mathrm{N}$-acyl-homoserine lactones, such as $\mathrm{N}$-acyl-3-amino- $5 \mathrm{H}$-furanone effectively block LuxR protein preventing cognate signal molecules binding. A review concerning the influence of natural and synthetic analogues of AHLs on QS of Gram-negative bacteria has been recently presented by Geske et al. (2008).

Any factor that interferes with the QS of pathogenic bacteria by inactivating of signal molecules and affecting the expression of the target genes, might be an excellent tool for the development of antibacterial therapies. Since the low molecular weigth compounds mentioned above enables inhibition of the QS mechanism, an alternative strategy is offered by AHL-degrading enzymes, which seems to be one of the most potent approaches for silencing QS.

Table 1. AHL-degrading enzymes described for various bacterial species

\begin{tabular}{|c|c|c|c|c|c|}
\hline Bacterial strain & Gene/protein & $\begin{array}{l}\text { Protein size } \\
(\mathrm{kDa})\end{array}$ & $\begin{array}{l}\text { Number of } \\
\text { amino acids }\end{array}$ & Enzymatic activity & REFERENCES \\
\hline Bacillus sp. & aiiA/AiiA & 28 & 250 & AHL lactonase & $\begin{array}{l}\text { Dong et al., 2000; } 2002 \\
\text { Wang et al., 2004 }\end{array}$ \\
\hline B. thuringiensis & aiiA/AiiA & 28 & 250 & AHL lactonase & $\begin{array}{l}\text { Dong et al., } 2002 \\
\text { Lee et al., } 2002\end{array}$ \\
\hline Arthrobacter sp. & ahlD/AhlD & 31 & 273 & AHL lactonase & Park et al., 2003 \\
\hline A. tumefaciens & attM/AttM & 29 & 264 & AHL lactonase & Zhang et al., 2002 \\
\hline A. tumefaciens & aiiB/AiiB & nd. & nd. & AHL lactonase & $\begin{array}{ll}\text { Zhang et al., } & 2002 \\
\text { Carlier } \text { et al., } & 2003 \\
\end{array}$ \\
\hline Rhodococcus sp. & nd. & nd. & nd. & AHL lactonase & Park et al., 2006 \\
\hline R. erythropolis & $q s d A / Q s d A$ & 36 & 323 & AHL lactonase & Uroz et al., 2008 \\
\hline V. paradoxus & nd. & nd. & nd. & AHL acylase & $\begin{array}{ll}\text { Zhang et al., } 2002 \\
\text { Carlier et al., } & 2003 \\
\end{array}$ \\
\hline R. eutropha & aiiD/AiiD & 84 & 794 & AHL acylase & Lin et al., 2003 \\
\hline P. aeruginosa & $p v d Q / P v d Q$ & 80 & 762 & AHL acylase & $\begin{array}{l}\text { Huang et al., } 2003 \\
\text { Sio et al., } 2006\end{array}$ \\
\hline$P$. aeruginosa & quiP/QuiP & 90 & 847 & AHL acylase & Huang et al., 2006 \\
\hline Anabaena sp. & all3924/AiiC & nd. & 847 & AHL acylase & Romero et al., 2008 \\
\hline Streptomyces sp. & ahlM/AhlM & 86 & 804 & AHL acylase & Park et al., 2005 \\
\hline Comamonas sp. & nd. & nd. & nd. & AHL acylase & Uroz et al., 2006 \\
\hline R. erythropolis & nd. & nd. & nd. & AHL acylase & Uroz et al., 2005 \\
\hline Acinetobacter sp. & nd. & nd. & nd. & nd. & Kang et al., 2004 \\
\hline Delftia sp. & nd. & nd. & nd. & nd. & Jafra et al., 2006b \\
\hline Ochrobactrum sp. & nd. & nd. & nd. & nd. & Jafra et al., 2006b \\
\hline
\end{tabular}

nd., not determined 


\section{ENZYMATIC DEGRADATION OF AHLS}

Many different bacteria belonging to various genera have been reported to express activity degradating AHLs (Table 1). The chemical structure of AHLs suggests that the degradation of such molecules may occur in four different ways (Fig. 3). Two of them lead to the degradation of the homoserine lactone ring mediated by lactonase or decarboxylase. Two others cause cleavage of AHL to a homoserine lactone and a free fatty acid moiety as reaction products of acylase (syn. amidase) or deaminase (Dong \& Zhang, 2005).

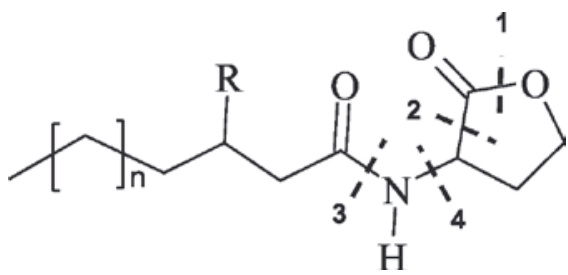

Figure 3. The possible ways of enzymatic degradation of AHLs.

Broken lines mark position of possible cleavages by following enzymes: $\mathbf{1}$, lactonase; $\mathbf{2}$, decarboxylase; $\mathbf{3}$, acylase; 4, deaminase (according to Dong \& Zhang, 2005).

Only two groups of AHL-degrading enzymes of the four mentioned above have been identified so far: AHL lactonases, the second AHL acylases (syn. AHL amidases) [EC 3.1.1.81]. The mechanism of action of AHL acylases is based on the cleavage of the amide carbon-nitrogen bond between fatty acid and homoserine lactone moiety, therefore biochemically the enzyme is an amidase [EC 3.5.1.4] and according to the proper biochemical nomenclature, should be called AHL amidase. However, researchers working on AHL degradation commonly use term AHL acylase for this particular group of enzyms; for this reason in this paper we use this generally accepted name as well.

\section{AHL LACTONASES}

AHL lactonases hydrolyze the lactone ring in the homoserine moiety of AHLs, whithout affecting the rest of the signal molecule structure (Fig. 4) (Dong et al., 2000; 2001; Leadbetter, 2001).

The occurrence of AHL lactonases does not seem to be connected with taxonomic classification, as they have been found in poorly related species of bacteria (see Table 1).

One of the first described and the best characterized AHL-lactonases is $\mathrm{AiiA}_{24 \mathrm{~B} 1}$, the product of the aiiA gene from Bacillus sp. 24B1 (Dong et al., 2000). At the time of study, the amino-acid sequence of this enzyme showed low similarity to enzymes of known sequence. Yet, the obtained data was sufficient to identify two main amino-acid motifs in the AiiA amino acid sequence (Dong et al., 2000). The first one, ${ }^{104}{ }^{\text {HLHFDHAG }}{ }^{111}$ is characteristic of metal-dependent $\beta$-lactamases, whereas the second one, ${ }^{165} \mathrm{HTPGHTPGH}^{173}$, is similar to the zinc-binding motif typical of metal-dependent hydrolases.

A

\section{AHL lactonase}

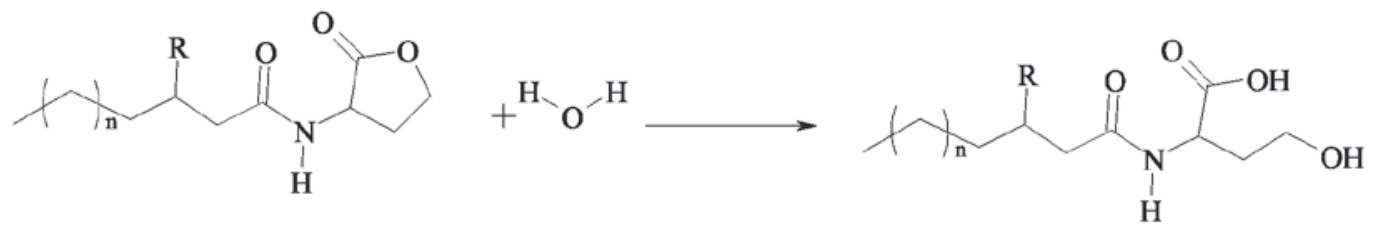

AHL

acyl-homoserine

B

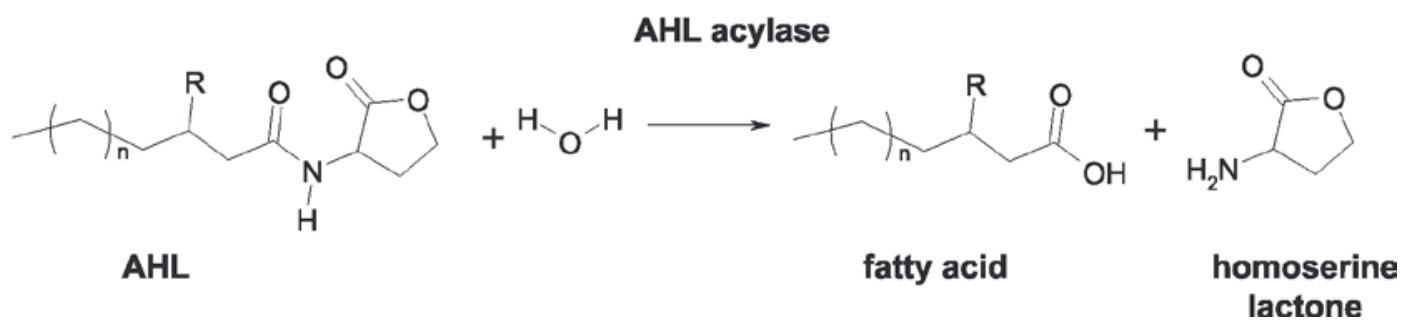

Figure 4. Mechanism of AHL-degrading enzymes.

A. Mode of AHL lactonase action. B. Mode of AHL acylase action. 
The studies of Wang et al. (2004) indicated that this motif does not bind metal ions and represents a new catalytic module responsible for AHL degradation (unlike in metal-dependent hydrolases). The crystal structure of AHL lactonase of $B$. thuringensis subsp. kurstaki (AiiA ${ }_{\text {ВтК}}$ ) (Kim et al., 2005; Liu et al., 2005) demonstrated, however, two zinc ions in the active centre of the enzyme. Therefore the first indication of Wang et al. (2004) suggesting that the $\mathrm{AiiA}_{24 \mathrm{~B} 1}$ might not be a metalloprotein is rather unlikely. The presence of the 'His ${ }^{106}-\mathrm{X}$-Asp ${ }^{108}$-His ${ }^{109}-59 \mathrm{X}-\mathrm{His}^{169}$. $21 \mathrm{x}-\mathrm{Asp}{ }^{191}$, motif is essential for the enzyme activity and allows classification of the enzymes into the AHL lactonase family. Homologues of AiiA lactonase were discovered in many bacteria belonging to the Bacillus genus. All of them show high nucleotide sequence similarity, greater than $90 \%$ (Dong et al., 2002; Lee et al., 2002; Kim et al., 2005).

During recent years more bacteria possessing AHL-lactonase activity were described: Agrobacterium tumefaciens (Zhang et al., 2002; Carlier et al., 2003), Arthrobacter sp. and Rhodococcus sp. (Park et al., 2003; 2006) and R. erythropolis (Uroz et al., 2008).

The AHL lactonase activity observed in Arthrobacter sp. (Park et al., 2003) depends on the ahlD gene product. AhlD degrades various AHLs regardless of the length of the acyl side chain or oxidation state (Park et al., 2003). A search of amino-acid sequence databases has revealed that the AhlD amino-acid sequence is in $27 \%$ similar to a sequence of Bacillus stearothermophilus and in 23\% to one of Klebsiella pneumoniae (Park et al., 2003). The presence of AHL-degrading activity in cells of these bacteria was confirmed by bioassay for AHL-degradation (Park et al., 2003).

An AttM AHL lactonase was identified in $A$. tumefaciens (Zhang et al., 2002). This bacterium is known to employ QS for cell-to-cell conjugal plasmid transfer (Fuqua \& Winans, 1994). The expression of the attM gene is growth phase-dependent, and controlled by several different factors (Zhang et al., 2002; 2004). Initially, the control of QS-dependent $\mathrm{Ti}$ plasmid transfer by titration of the signal molecules was proposed as the main role of AttM lactonase (Zhang et al., 2002). The attM gene is located in the pAt plasmid (Carlier et al., 2003) and its product might be involved in recycling of AHLs molecule, as A. tumefaciens C58 derivatives lacking the pAt plasmid excreted a much higher level of the AHL (oxo-C8-HSL) in comparison with the plasmidbearing C58 strain (Zhang et al., 2002). However, recent work of Chai et al. (2007) suggests that AttM plays a more general role in A. tumefaciens metabolism. Furthermore, the most recently published work of Khan and Farrand (2009) has excluded the role of AttM lactonase in conjugal Ti plasmid transfer. Both aspects will be discussed further.
According to phylogenetic analyses, all described lactonases and their homologues can be classified into two clusters: the AiiA-like cluster and the AttM-like cluster (Dong \& Zhang, 2005). Members of the AiiA-like cluster are more than 90\% identical while the AttM-like cluster members show only $30-58 \%$ homology in peptide sequence and are less than $25 \%$ identical with the AiiA-like cluster members. Recently Uroz et al. (2008) reported a novel class of AHL-lactonases from Rhodococcus erythropolis strain W2, described later.

\section{AHL ACYLASES}

These enzymes hydrolyze the amide bond between the acyl side chain and the homoserine lactone in the AHL molecules generating the free fatty acid and the homoserine lactone (Fig. 4) (Leadbetter \& Greenberg, 2000). In most cases degradation products are further metabolized and finally used by the bacteria as carbon, nitrogen or energy sources.

To the present, nine AHL acylases from various groups of bacteria have been reported. One of the first to be described was an enzyme from Gramnegative bacterium Variovorax paradoxus VAI-C strain (Leadbetter \& Greenberg, 2000). Initial investigations indicated a wide range of AHLs degradation capacity of this bacterium. $V$. paradoxus when grown at the presence of AHL, released into a growing medium a homoserine lactone as a main degradation product while a fatty acid was utilized to generate energy. Untill now, however, the gene responsible for AHL degradation has not been cloned and the enzymatic activity involved in AHL decay by $V$. paradoxus is poorly characterised.

Of the nine AHL acylases reported, five have been described in detail: AiiD from Ralstonia eutropha (Lin et al., 2003), PvdQ and QuiP from P. aeruginosa (Huang et al., 2003; 2006; Sio et al., 2006), AhlM from Streptomyces sp. (Park et al., 2005) and AiiC from Anabaena sp. PCC7120 (Romero et al., 2008).

Another well studied, the AHL acylase, AiiD, was found in R. eutropha (Lin et al., 2003). AiiD is most similar to aculeacin A acylase from Actinoplanes utahensis and shows some sequence homology with cephalosporin acylase and other N-terminal nucleophile (Ntn) hydrolases (Lin et al., 2003). Data presented by Brannigan et al. (1995) and Oinonen and Rouvinen (2000) suggested that such N-terminal hydrolases are synthesized as inactive proenzymes. The enzyme precursor undergoes autoproteolysis and becomes a mature active AHL acylase composed of two subunits. AiiD shows high substrate specificity and degrades only AHLs and, above all, exhibits preference for the degradation of long chain AHLs (Lin et al., 2003). 
In $P$. aeruginosa a complex QS mechanism is involved in the regulation of pathogenicity factors synthesis, so that determining the AHL-degrading activity was of particular interest. During preliminary studies Huang et al. (2003) isolated and analyzed a close homologue of AiiD acylase, PvdQ protein. PvdQ possesses strong preferences for the decomposition of long-chain AHLs (with the acyl side chain longer than 8 carbons) and does not degrade the short ones. PvdQ activity is sufficient for AHLs degradation, although the podQ negative mutants remains capable of expressing AHLs degrading activity. Such observations have led to the conclusion that $P$. aeruginosa has to express another AHL-degrading factor to enable signal molecule disintegration during its growth. In 2006, the same group and the group of Sio et al. (2006) described a second AHL acylase present in $P$. aeruginosa, namely QuiP (the PA2385 gene). Further study has revealed that QuiP is expressed constitutively during growth and its activity is sufficient to inactivate long-chain AHLs produced by Pseudomonas. Mutants in quiP gene exhibit growth defects during cultivation in medium supplemented with 3-oxo-C12-HSL as the only carbon and/or nitrogen source (Huang et al., 2006; Sio et al., 2006).

For a long time the presence and activity of AHL acylase was observed and investigated only in Gram-negative bacteria. The first example of such activity in Gram-positive bacteria was revealed in Streptomyces sp. (Park et al., 2005). The study resulted in isolation of Strepotmyces sp. strain able to degrade AHLs by the secreted AHL-degrading enzyme. The protein encoded by the ahlM gene was identified as AHL acylase on the basis of mass spectrometry analyses of the product of AHL degradation. The AhlM acylase is able to degrade not only AHLs but also penicillin $G$, that suggests a low specificity of this enzyme. Many AHL acylases are subject to post-transcriptional processing from a modified inactive proenzyme into a native, mature enzyme. Heterologous ahlM gene expression in E. coli showed that the synthesized protein is inactive, does not undergo any processing and is not secreted outside the cell. Therefore the ahlM gene was cloned and expressed in Streptomyces lividans which, by itself, does not show an AHL-degrading activity. The maturation of AhlM acylase in Streptomyces still needs to be carefully investigated.

Most recently, the AHL acylase was described in the cyanobacterium Anabaena sp. PCC7120 (Romero et al., 2008). The gene all3924 whose product showed AHL-degrading activity was cloned and named aiiC. The recombinant protein was proven to have the AHL acylase activity by standard tests. Genomic analyses have revealed the presence of aiiC sequences in the genomes of various nitrogen-fixing cyanobacteria.

The investigation of the AHL-degrading activity in various bacteria is ongoing. Studies of Uroz et al. (2006) have revealed that an amidolytic activity of Comamonas sp. strain D1 is involved in AHL decay, but the gene responsible for this activity has not been cloned so far. Interestingly, the AHL-degradation activity of Comamonas sp. D1 strain requires active growth of the bacteria as has been also reported for R. erythropolis (Uroz et al., 2005; Park et al., 2006). However, in the case of $R$. erythropolis W2 another AHL-degrading activity towards 3-oxo-C12-HSL was observed in the crude cell extract. Studies of $R$. erythropolis strain W2 have revealed the presence of two distinct types of AHL-degrading enzymes (Uroz et al., $2005 ; 2008)$, as discussed in the following chapter. Furthermore, our study has shown, that a bacterium from the genus Ochrobactrum strain A44 has an ability to degrade AHLs (Jafra et al., 2006b). The AHL lactonase activity was excluded in this case, indicating that this bacterium employs a different type of AHL-degrading enzyme, possibly an AHL acylase. Ochrobactrum sp. A44 cells are able to break down a wide spectrum of AHLs with or without an oxo-substituent and varying in the acyl-side chain length.

Summerising, the AHL acylases described to date belong to the N-terminal hydrolase superfamily and are composed of two or more subunits. Usually, four domains may be distinguished in their aminoacid sequences: signal peptide, $\alpha$-subunit, linear spacer and $\beta$-subunit. AHL acylase proenzyme has to be processed into an active enzyme by autoproteolysis (Kim et al., 2000). Only one of the characterized enzymes, AhlM from Streptomyces sp., was reported to be secreted outside the bacterial cell, the remaining ones are known to act intracellularly (Park et al., 2005). The genes encoding AHL acylases are widespread in bacteria, both Gram-negative (AiiD from R. eutropha (Lin et al., 2003), PvdQ and QuiP from P. aeruginosa (Huang et al., 2003; 2006)) and Gram-positive (AhlM from Streptomyces (Park et al., 2005)) as well as cyanobacteria Anabaena sp. (Romero et al., 2008).

\section{A UNIQUE AHL DEGRADATION SYSTEM IN RHODOCOCCUS sp.}

A very interesting AHL-degrading system has been found in Rhodococcus sp. So far, three various AHL-degrading enzymatic activities have been described in this genus (Uroz et al., 2005; 2008; Park et al., 2006). For the first time, Uroz et al. (2003) observed an AHL-degrading activity of 
R. erythropolis strain W2 with a preference for 3oxo-substituted AHLs. The following studies have revealed that 3-oxo-AHLs are converted into their 3-hydroxy-derivatives by means of an oxidoreductase activity (Uroz et al., 2005). This type of AHL degradation was observed only during bacterial growth, but not when cell extract was tested. The oxidoreductase activity is not specific solely to AHLs with a 3-oxo-substituent. This enzyme is also able to reduce AHL derivatives such as $\mathrm{N}-(3-$ oxo-6-phenylhexanoyl) homoserine lactone (which contains an aromatic acyl chain substituent) or 3-oxododecanamide (which lacks the homoserine lactone ring). Further investigation of AHL decomposition by $R$. erythropolis W2 has resulted in the discovery of another type of enzymatic activity - AHL acylase (Uroz et al., 2005). A year later Park et al. (2006) reported a third enzymatic activity involved in AHL decomposition by Rhodococcus strains - an AHL lactonase. Two Rhodococcus isolates - strains LS31 and PI33 - were able to utilize AHLs, but with different AHL-degrading spectra. The most recent studies of Uroz et al. (2008) described the genetic background of the AHL lactonase activity in this genus. The qsdA gene, first described for R. erythropolis strain W2, encodes a novel class of wide-spectrum substrate AHL lactonases. The QsdA lactonase belongs to the phosphotriesterase (PTE) family of zinc-dependent metalloproteins. It is not related to any known Zn-dependent AHL lactonases from the glyoxylase family, or to any known AHL acylase from the $\beta$-lactamase family. The $q s d A$ gene was found in almost all tested strains from the Rhodococcus genus but not in R. erythropolis DCL14, although this strain is still able to degrade AHLs. The PTE lactonase is exclusively found in the Rhodococcus genus, in strains capable of hydrolizing AHLs (Uroz et al., 2008). At the moment Rhodococcus is the unique species of bacteria which possesses three different types of AHL-degrading activities.

\section{DEGRADATION OF BACTERIAL AHLs IN MAMMALIAN CELLS}

The AHL lactonase activity has also been reported in mammalian cells. Eukaryotic lactonases, named paraoxonases (PONs), isolated from human airway epithelia behave in a different way than the previously described bacterial enzymes (Billecke et al., 2000; Draganov et al., 2000; Teiber et al., 2003; Chun et al., 2004). Three types of PONs, including PON1, PON2 and PON3, are known to hydrolyze a wide range of chemicals (Draganov \& La Du, 2004). They share $60 \%$ of amino-acid sequence identity and require $\mathrm{Ca}^{2+}$ ion for activity. Further analyses have shown that PON1, PON2 and PON3 differ in their substrate preferences, the latter two lacking the paraoxonase activity. Still all three enzymes are able to hydrolyze the lactone ring of AHL (Draganov et al., 2005). Studies of Ozer et al. (2005) have revealed a strong activity of purified PON1 from human serum against 3-oxo-C12-HSL of $P$. aeruginosa. PONs display the highest degrading activity against longchain AHL molecules, such as 3-oxo-C12-HSL and are less effective with short-chain AHLs (Chun et al., 2004; Yang et al., 2005). As 3-oxo-C12-HSL plays an important role in QS of $P$. aeruginosa, a PON activity towards this molecule indicates the importance of these enzymes in host cell protection against microbial infection. The observation of a PON AHLdegrading activity in serum of several mammal supports this hypothesis.

\section{SUBSTRATE PREFERENCES OF AHL-DEGRADING ENZYMES}

The AHL-degrading bacteria usually show some degree of substrate preference. These preferences are a direct result of the AHL-degrading enzymes amino-acid structure and/or co-factor involvement. Also the occurrence of different types of AHL produced by the various bacteria present in the natural environment influence the substrate preferences (Huang et al., 2003; 2006; Carlier et al., 2003; Lin et al., 2003).

Most AHL lactonases known which hydrolyse the homoserine lactone ring do not display any preferences for the length of the carbon acyl side chain (Wang et al., 2004; Dong \& Zhang, 2005). Good examples are the AiiA and AhlD lactonases from $B a-$ cillus sp. (Dong et al., 2000; Wang et al., 2004; Lui et al., 2005; Kim et al., 2005) and Arthrobacter sp. (Park et al., 2003), respectively. The AhlD lactonase from Arthrobacter sp. is able to degrade a great variety of AHLs, including C4-HSL (Park et al., 2003). The same was observed for Rhodococcus sp. AHL lactonases (Uroz et al., 2005; Park et al., 2006).

Among AHL acylases, only one example of broad range AHL-degrading enzyme has been described so far (Romero et al., 2008). The AiiC acylase from Anabaena sp. can hydrolyze a set of AHLs, that differ in the acyl chain length and substitution, including C4-HSL, however, it shows preference for long-chain AHLs (C10-HSL and above).

Such a broad degradation ability is not usually observed in the case of other known AHL-degrading enzymes which usually show preference for one particular signal molecule or a specific group of AHLs. QuiP and PvdQ, the AHL acylases from $P$. aeruginosa active exclusively against 3-oxo-C12-HSL 
(Huang et al., 2003; 2006) are excellent examples. Some substrate preference has been observed in $R$. eutropha producing AiiD, the AHL acylase which only degrades unsubstituted and 3-oxo-substituted AHLs with acyl side chains at least 8 carbons long (Lin et al., 2003). AHL-degrading bacteria, even if their AHL-degrading enzymes do not exhibit preference for the AHL side chain length, usually break down AHLs with the acyl side chains containing at least 6 carbons (Uroz et al., 2003; Zhang 2003; Dong \& Zhang 2005; Jafra et al., 2006b).

\section{LOCALIZATION OF AHL-DEGRADING ACTIVITY}

Most of the AHL-utilizing bacterial strains were reported as soil or rhizosphere inhabitants (Lee et al., 2002; Huang et al., 2003; Wang et al., 2004; 2006; Park et al., 2005; Yoon et al., 2006). Their living conditions and nutrient availability are functions of the occupied soil environment. This environment shows large variability in the availability of nutrients, water, vital ions, and oxygen. Such an unstable environment would not usually create optimal conditions for the AHL-degrading enzymes. Therefore intercellular AHL-degrading enzymes which act in fairly constant, optimal reaction conditions and are isolated from the external environmental appeared in evolution and predominate in bacteria (Leadbetter \& Greenberg, 2000; Dong et al., 2000; 2001; 2002; Leadbetter, 2001; Zhang et al., 2002; Carlier et al., 2003; Park et al., 2003; Huang et al., 2003; Lin et al., 2003; Molina et al., 2003; Uroz et al., 2003; 2005; Wang et al., 2004; Liu et al., 2005; Kim et al., 2005; Jafra et al., 2006b).

Both AHL lactonases and AHL acylases were reported to be cytoplasmic, although in the case of the recently reported AiiC acylase from cyanobacteria (Romero et al., 2008) the predicted secondary structure of a putative transmembrane domain in the $\mathrm{N}$-terminal region indicates its periplasmic localization. The cytoplasmic, intracellular localization of AHL-degrading enzymes suggests that extracellular degradation is rather an exception. And the first example of the extracellular AHL-degrading enzyme in the literature is the AhlM acylase of Streptomyces sp. (Park et al., 2005).

\section{THE ROLE OF SIGNAL MOLECULE-DEGRADING ENZYMES}

The examples of AHL-degrading activities described above show that QQ enzymes are wide spread in the natural environment. The reason why bacteria have developed the system allowing them to degrade AHLs is an interesting subject of research.
Some data indicate that the AHL degradation products may serve as a source of nitrogen or/and carbon and an energy reservoir (Leadbetter \& Greenebrg, 2000; Huang et al., 2003; Park et al., 2003; Sio et al., 2006; Yang et al., 2006; Yoon et al., 2006; Chai et al., 2007). Such a situation is observed for $V$. paradoxus which utilizes the fatty acid released from AHL as an energy source (Leadbetter \& Greenberg, 2000). Arthrobacter sp. expressing AhlD lactonase (Flagan et al., 2003; Park et al., 2003; Yang et al., 2006) and the soil-borne Burkholderia strains (Yang et al., 2006) are other examples. The soil bacterium Nocardioides kongjuensis also uses the AHL degradation products as a carbon source (Yoon et al., 2006).

Another case is $P$. aeruginosa expressing the PvdQ enzyme (Huang et al., 2003; Sio et al., 2006). One of the AHL degradation products is toxic for $P$. aerugionosa and as such has to be degraded effectively. The other product of AHL degradation, a fatty acid, is utilized by this bacterium as a source of energy (Huang et al., 2003). The PvdQ AHL acylase thus secures an additional carbon and energy source from AHL hydrolysis when the bacteria grow in a nutrient-poor environment. This AHL acylase synthesis is induced or repressed under the control of environmental conditions (Huang et al., 2003). Additionally, $P$. aeruginosa synthesizes another AHL acylase named QuiP which controls QS-dependent virulence processes (Huang et al., 2006). The QuiP activity is sufficient for AHL utilization during $P$. aeruginosa growth, both in natural environments and in in vitro tests. Unlike PvdQ, the QuiP is expressed constitutively (Huang et al., 2003; 2006).

Expression of signal molecule-degrading enzymes could also ensure success in competition for the limited natural resources, as has been reported in the case of Bacillus thuringiensis and Pectobacterium carotovorum mutual interactions. B. thuringiensis does not produce factors that could affect the $P$. carotovorum growth but biosynthesis of AiiA lactonase by $B$. thuringiensis significantly reduces $P$. carotovorum adaptability in the environment. Bacillus strains without an AHL-degrading activity do not exhibit such ability (Dong et al., 2004). This example leads to the conclusion that switching the QS systems on and off by various AHL degraders might play a great role in the environment in mutual, both symbiotic and pathogenic, bacterial interactions.

Recently, Park et al. (2008) revealed that the AiiA lactonase of $B$. thuringensis is essential for rhizosphere colonization by this bacterium and its survival in the soil. A mutant defective in AiiA lactonase synthesis was unable to successfully colonize the test plants' rhizosphere and its viability was significantly reduced. The limited persistence of $B$. thuringiensis aiiA mutant in natural for B. thuringnesis niche was demonstrated. This finding sug- 
gested that AiiA lactonase might be involved in microbial competitivenss in the rhizosphere and helps bacteria to survive on the plant root. These authors also suggested that AiiA lactonase can participate in bacterial metabolism.

An interesting concept explaining the role of AHL degradation in the environment has been posted by Kaufmann et al. (2005). The 3-oxo substituted AHLs are subject to an unusual Claisen-like condensation reaction resulted in the tetramic acid derivatives formation. Both, the 3-oxo AHLs and their nonenzymatically-formed products possess bacteriocidal activity towards Gram-positive, but not Gram-negative bacteria. These tetramic acid derivatives are also able to complex metal ions (e.g., iron) important for bacterial growth in natural environment. This finding supported the hypothesis that AHL-degrading enzymes of Gram-positive bacteria, such as AHL lactonases from Bacillus evolved in order to control the antibacterial activity of AHLs and to enhance bacterial survival in natural environment.

Another example of the use of AHL-degrading enzymes by bacteria comes from A. tumefaciens. The AttM AHL lactonase from this bacterium has been proposed to help control the conjugation and Ti plasmid transfer between members of its own population (Zhang et al., 2002; Carlier et al., 2003). For conjugation a high concentration of AHLs is required. It is essential to complete conjugation while the population is still expanding. At the stationary phase the number of bacteria does not change and conjugation, even if it occurs, does not ensure further Ti plasmid transfer to new cells. Expression of the attM gene is negatively regulated by the AttJ repressor, which is switched off when A. tumefaciens population enters to the stationary phase (Zhang et al., 2002). Taking this into acount, it was suggested that timedependent AttM synthesis and activity lead to the degradation of autoinducers and inhibition of $\mathrm{Ti}$ plasmid conjugation (Zhang et al., 2002). Another explanation for the role of AttM AHL-degrading activity in A. tumefaciens cells was raised by Chai et al. (2007). The AHL-degrading enzymes, such as AttM, evolved by selection for degradation of the compounds found in the environment, and the AHL degradation is purely coincidental. Chai et al. (2007) confirmed biochemically the role of the attKLM operon in the conversion of $\gamma$-butyrolactone (GBL) to $\gamma$-hydroxybutyrate (GHB) then to succinic semialdehyde (SSA) and finally to succinate (SA) which was previously observed by Carlier et al. (2003). The final product of this metabolic pathway, SA, enters the tricarboxylic acid cycle of the bacterium. The results showed, that attM expression is not induced by the presence of any type of AHL, but is strongly induced by GHB and/or SSA. This finding indicated that the AttM enzyme evolved by selection for substances other than AHLs and AHL degradation is a side effect. Further studies revealed that some plant seedling exudates, GHB-like compounds, which might induce the transcription of attM by releasing AttJ from the gene promoter, interfere in cell-to-cell signaling mediated by AHLs (Chai et al., 2007).

Recently published studies of Khan and Farrand (2009) addressed the question of the role of AttM lactonase (named by those authors BlcC for $\gamma$-butyrolactone catabolism) in conjugative transfer of Ti plasmid of A. tumefaciens. The blcC mutatation did not affect the AHL signal molecules accumulation or the conjugal ability of these bacteria in plant tissue (Khan \& Farrand, 2009). These findings counter the previous hypothesis of the AttM (BlcC) lactonase role in controling $\mathrm{Ti}$ plasmid transfer, support the concept of 'accidental' degradation of AHL and prove the major activity of $\mathrm{BlcC}$ in degradation of plant-generated GHB-like compounds.

One might conclude that the AHL-degrading enzymes can play different biological role in the various bacteria producing them. Most recent studies indicate, that this role is not always dedicated specifically to AHL-degradation but aids the bacteria to benefit or/and survive in the natural environment.

\section{PERSPECTIVES OF QQ APPLICATION}

The biotechnological applications of AHL degradation as a new, promising method for fighting detrimental bacteria have foccused researchers' attention. As many of the human and plant bacterial pathogens employ the AHL-based QS mechanism for regulation of the pathogenicity determinant synthesis or biofilm formation, the application of $\mathrm{QQ}$ strategy may be an alternative approach for fighting these microorganisms.

Fighting bacterial plant pathogens remains difficult and ineffective. The most extensive studies of QQ application have been performed on the plant pathogenic bacteria from the former pectolytic Erwinia genus. These bacteria, which nowadays are classified into three different species (Pectobacterium atrosepticum, P. carotovorum subsp. carotovorum and Dickeya sp.) are the causative agents of soft rot diseases of many economically important plants. They are also responsible for the blackleg disease of potato plants in temperate climate (Pérombelon \& Kelman, 1980; Pérombelon, 2002; Ma et al., 2007; de Haan et al., 2008). As the AHL-dependent QS mechanism is involved in bacterial pathogenesis (for review see: Whitehead et al., 2002), QS interference strategies 
are proposed as a new, alternative approach to the attenuation of bacterial infection development in plants. The first strategy relies on introduction of a gene coding AHL synthase directly to the plant cells and its stable expression in the plant tissue (Fray et al., 1999; Mäe et al., 2001; Fray, 2002; Toth et al., 2004); the second one employs AHL-degrading bacteria for plant protection against Pectobacteria (Uroz et al., 2003; 2005; Dong et al., 2004; Jafra et al., 2006b). Yet another approach involves heterologous expression of genes encoding AHL-degrading enzymes in pathogen cells or in plant tissue (Dong et al., 2001). The success of preliminary research has enabled a new and alternative strategy for controlling bacterial infections.

As bacterial populations use signal molecules to sense cell density and coordinate their own behavior, the artificially increased level of AHLs (due to expression of AHL-synthase gene in the plant tissue) makes bacteria to misinterprete the population size. Such misinterpretation leads to the production of virulence determinants long before the pathogen population is large enough to sustain infection in the plant which in turns would enable the pathogens invasion to be overcome (Mäe et al., 2001). However, Toth et al. (2004) reported that AHL production by transgenic plants not only can induce bacterial infection development but also makes the plants more sensitive and susceptible to infection caused by pectolytic Erwinia (Pectobacteria). This is in contradiction to earlier results obtained by Mäe et al. (2001).

Application of bacterial cells producing AHLdegrading enzymes prevents maceration of plant tissue by the tested pathogens (Uroz et al., 2003; 2005; Jafra et al., 2006b). This strategy gives the opportunity for direct application of AHL-degrading bacteria as biological control agents of plant bacterial diseases.

Transgenic potato and tobacco plants expressing the gene encoding AiiA lactonase manifested strong resistance against infection by $P$. carotovorum subsp. carotovorum (Dong et al., 2001). This was the first example of purposeful usage of the AHL-degrading enzyme for attenuation of infection symptoms development in plants, however, this strategy requires the genetic modification of higher organisms which is not universally accepted.

Introduction of genes encoding AHL-degrading enzymes resulted in a decrease of the AHL level in the surrounding environment and hampered the ability of $P$. carotovorum to prolong infection (Dong et al., 2000). Heterologous expression of the aiiA gene encoding the AiiA lactonase from Bacillus sp. in P. carotovorum cells, impedes production of exoenzymes, and disease symptoms development. A similar approach was used for two other important plant pathogens Burkholderia thailandensis and Erwinia amylovora where AHL lactonase encoded by aiiA gene homologues was expressed (Ulrich, 2004; Molina et al., 2005). The same approach was employed to study the silencing of the hierarchical QS system of $P$. aeruginosa. In this case, it resulted in reduction of signal amount of the first QS system (3-oxo-C12-HSL) and in consequence prevented accumulation of the second QS system signal molecule (C4-HSL) (Reimmann et al., 2002). The pathogenicity factor synthesis and swarming motility were markedly reduced. However, the fading of the signal did not influence the bacterial cell adhesion capacity and did not interfere with surface colonization by these bacteria. Park et al. (2005) demonstrated that addition of purified AhlM protein to the growth medium of $P$. aeruginosa eliminated 3-oxo-C12-HSL and reduced and delayed C4-HSL accumulation and strongly decreased virulence factor synthesis.

The above examples show that, the AHL-degrading enzymes together with QS inhibitors may be successfully used to disrupt bacterial cell to cell communication and to control bacterial infections.

\section{INFLUENCE OF QQ ON SOIL ENVIRONMENT}

For the reason, that a signal molecule degradation does not always lead to the suppression of negative effects and sometimes the benefits do not outweigh the risks, the subject needs further and deeper studies. This can occur, especially in the natural environment of the soil, where Rhizobium, Sinorhizobium and Bradyrhizobium use the AHL-mediated QS mechanism for controlling plant nodulation. Nodulation is important not only for plants but also in agriculture to increase the crop production in areas of poor soil nitrogen availability as this process is the only possibility to bind air-borne nitrogen, transform it into inorganic salts and ensure its utilization. Nodulation cannot occur if the QS is suppressed in these bacteria (Rosemeeyer et al., 1998; Marketon \& Gonzalez, 2002; Hoang et al., 2004; for review: Gonzalez \& Keshavan, 2006).

The soil-borne bacterium Pseudomonas aerofaciens competes with soil fungi from the genus Fusarium by quorum sensing-dependent and AHL-based production of an antifungal antibiotic phenazine which suppresses Fusarium growth. P. aerofaciens is used as a protective agent against Fusarium infections in plants (de Boer, 2000). Since phenazine can not be synthesized in an AHL-deficient environment, AHL degradation could cause problems rather than bring benefits in this particular case (Whistler \& Pierson, 2003). 


\section{FINAL REMARKS}

Numerous reports show that bacteria become resistant to a great variety of antibiotics, which results in the reduction in the potential use of pharmaceuticals and their availability for humans. Such observations lead straightforwardly to the conclusion that new therapies, alternative to antibiotic usage, ought to be invented in the near future.

QS inhibition by enzymatic degradation of signal molecules is one such option. It has been reported that most, if not all bacteria, both Gram-negative and Gram-positive, use a sort of QS for controlling population-dependent behavior. Therefore even if the signal molecules exploited in these processes have many distinct structures, it is usually possible to find an enzyme which could destroy any one of them.

\section{Acknowledgements}

The authors thank E. Lojkowska and D. Krzyżanowska for helpful discussion.

This work was supported by the Ministry of Science and Higher Education grant PBZ-KBN 112/ P06/2005.

\section{REFERENCES}

Adonizio A, Kong KF, Kalai M (2008) Inhibition of quorum sensing-controlled virulence factor production in Pseudomonas aeruginosa by south Florida plant extracts. Antimicrob Agents Chemother 52: 198-203.

Bainton NJ, Bycroft BW, Chhabra SR, Stead P, Gledhill L, Hill PJ, Rees CE, Winson MK, Salmond GP, Stewart GS et al. (1992) A general role for the lux autoinducer in bacterial cell signalling: control of antibiotic biosynthesis in Erwinia. Gene 116: 87-91.

Billecke S, Draganov D, Counsell R, Stetson P, Watson C, Hsu C, La Du BN (2000) Human serum paraoxonase (PON1) isozymes $\mathrm{Q}$ and $\mathrm{R}$ hydrolyze lactones and cyclic carbonate esters. Drug Metab Dispos 28: 1335-1342.

Brannigan JA, Dodson G, Duggleby HJ, Moody PC, Smith JL, Tomchick DR, Murzin AG (1995) A protein catalytic framework with an N-terminal nucleophile is capable of self-activation. Nature 378: 416-419.

von Bodman S, Farrand SK (1995) Capsular polysaccharide biosynthesis and pathogenicity in Erwinia stewartii require induction by an $\mathrm{N}$-acylhomoserine lactone autoinducer. J Bacteriol 177: 5000-5008.

von Bodman SB, Bauer WD, Coplin DL (2003) Quorum sensing in plant-pathogenic bacteria. Annu Rev Phytopathol 41: 455-482.

von Bodman SB, Majerczak DR, Coplin DL (1998) A negative regulator mediates quorum-sensing control of exopolysaccharide production in Pantoea stewartii subsp. stewartii. Proc Natl Acad Sci USA 95: 7687-7692.

de Boer M (2000) Combining Pseudomonas strains to improve biological control of fusarium wilt in radish. PhD thesis, Utrecht University, Utrecht, The Netherlands.

Carlier A, Uroz S, Smadja B, Fray R, Latour X, Dessaux Y, Faure D (2003) The Ti plasmid of Agrobacterium tumefa- ciens harbors an attM-paralogous gene, aiiB, also encoding N-acyl homoserine lactonase activity. Appl Environ Microbiol 69: 4989-4993.

Cha C, Gao P, Chen YC, Shaw PD, Farrand SK (1998) Production of acyl-homoserine lactone quorum-sensing signals by Gram-negative plant-associated bacteria. $\mathrm{Mol}$ Plant Microbe Interact 11: 1119-1129.

Chai, Y, Tsai CS, Cho H, Winans SC (2007) Reconstitution of the biochemical activities of the AttJ repressor and the AttK, AttL, and AttM catabolic enzymes of Agrobacterium tumefaciens. J Bacteriol 189: 3674-3679.

Chatterjee A, Cui Y, Hasegawa H, Leigh N, Dixit V, Chatterjee AK (2005) Comparative analysis of two classes of quorum-sensing signaling systems that control production of extracellular proteins and secondary metabolites in Erwinia carotovora subspecies. J Bacteriol 187: 8026-8038.

Chun CK, Ozer EA, Welsh MJ, Zabner J, Greenebrg EP (2004) Inactivation of Pseudomonas aeruginosa quorumsensing signal by human airway epithelia. Proc Natl Acad Sci USA 101: 3587-3590.

Claverys JP, Havarstein LS (2002) Extracellular-peptide control of competence for genetic transformation in Streptococcus pneumoniae. Front Biosci 7: d1798-d1814.

Diggle SP, Winzer K, Lazdunski A, Williams P, Camara M (2002) Advancing the quorum in Pseudomonas aeruginosa: MvaT and the regulation of $\mathrm{N}$-acylhomoserine lactone production and virulence gene expression. J Bacteriol 184: 2576-1286.

Diggle SP, Winzer K, Chhabra SR, Worrall KE, Camara M, Williams P (2003) The Pseudomonas aeruginosa quinolone signal molecule overcomes the cell density-dependency of the quorum sensing hierarchy, regulates rhl-dependent phenotypes at the onset of stationary phase and can be produced in the absence of LasR. Mol Microbiol 50: 29-43.

Dong YH, Zhang LH (2005) Quorum sensing and quorumquenching enzymes. J Microbiol 43: 101-109.

Dong YH, Xu JL, Li XZ, Zhang LH (2000) AiiA, an enzyme that inactivates the acylhomoserine lactone quorumsensing signal and attenuates the virulence of Erwinia carotovora. Proc Natl Acad Sci USA 97: 3526-3531.

Dong YH, Gusti AR, Zhang Q, Xu JL, Zhang LH (2002) Identification of quorum-quenching $\mathrm{N}$-acyl homoserine lactonases from Bacillus species. Appl Environ Microbiol 68: 1754-1759.

Dong YH, Wang LH, Xu JL, Zhang HB, Zhang XF, Zhang LH (2001) Quenching quorum-sensing-dependent bacterial infection by an $\mathrm{N}$-acyl homoserine lactonase. $\mathrm{Na}$ ture 411: 813-817.

Dong YH, Zhang XF, Xu JL, Zhang LH (2004) Insecticidal Bacillus thuringiensis silences Erwinia carotovora virulence by a new form of microbial antagonism, signal interference. Appl Environ Microbiol 70: 954-960.

Draganov DI, La Du BN (2004) Pharmacogenetics of paraoxonases: a brief review. Naunyn Schmiedebergs Arch Pharmacol 369:78-88.

Draganov DI, Stetson PL, Watson CE, Billecke SS, La Du BN (2000) Rabbit serum paraoxonase 3 (PON3) is a high density lipoprotein-associated lactonase and protects low density lipoprotein against oxidation. J Biol Chem 275: 33435-33442.

Draganov DI, Teiber JF, Speelman A, Osawa Y, Sunahara R, La Du BN (2005) Human paraoxonases (PON1, PON2 and PON3) are lacontases with overlapping and distinct substrate specificities. J Lipid Res 46: 1239-1247.

Eberhard A (1972) Inhibition and activation of bacterial luciferase synthesis. J Bacteriol 109: 1101-1105. 
Eberhard A, Burlingame AL, Eberhard C, Kenyon GL, Nealson KH, Oppenheimer NJ (1981) Structural identification of the autoinducer of Photobacterium fischeri luciferase. Biochemistry 20: 2644-2649.

Farah C, Vera M, Morin D, Haras D, Jerez CA, and Guiliani N (2005) Evidence for a functional quorum-sensing type AI-1 system in the extremophile bacterium Acidithiobacillus ferrooxidans. Appl Environ Microbiol 71: 7033-7040.

Flagan S, Ching WK, Leadbetter JR (2003) Arthrobacter strain VAI-A utilizes acyl-homoserine lactone inactivation products and stimulates quorum signal biodegradation by Variovorax paradoxus. Appl Environ Microbiol 69: 909-916.

Fray RG (2002) Altering plant-microbe interaction through artificially manipulating bacterial quorum sensing. Ann Bot 89: 245-253.

Fray RG, Throup JP, Daykin M, Wallace A, Williams P, Stewart GSAB, Grierson D (1999) Plants genetically modified to produce $N$-acylhomoserine lactones communicate with bacteria. Nature Biotech 17: 1017-1020.

Fuqua WC, Winans SC (1994) A LuxR-LuxI type regulatory system activates Agrobacterium Ti plasmid conjugal transfer in the presence of a plant tumor metabolite. J Bacteriol 176: 2796-2806.

Fuqua C, Winans SC (1996) Localization of OccR-activated and TraR-activated promoters that express two ABC-type permeases and the traR gene of Ti plasmid pTiR10. Mol Microbiol 20: 1199-1210.

Fuqua C, Greenberg EP (2002) Listening in on bacteria: acyl-homoserine lactone signalling. Nat Rev Mol Cell Biol 3: 685-695

Fuqua C, Parsek MR, Greenberg EP (2001) Regulation of gene expression by cell-to-cell communication: acyl-homoserine lactone quorum sensing. Annu Rev Genet 35: 439-468.

Fuqua WC, Winans SC, Greenberg EP (1994) Quorum sensing in bacteria: the LuxR-LuxI family of cell density-responsive transcriptional regulators. J Bacteriol 176: 269-275.

Gao M, Teplitski M, Robinson JB, Bauer WD (2003) Production of substances by Medicago truncatula that affect bacterial quorum sensing. Mol Plant Microbe Interact 16: 827-34.

Geske GD, O’Neill JC, Blackwell HE (2008) Expanding dialogues: from natural autoinducers to non-natural analogues that modulate quorum sensing in Gram-negative bacteria. Chem Soc Rev 37: 1432-1447.

Gonzalez JE, Keshavan ND (2006) Messing with bacterial quorum sensing Microbiol Mol Biol Rev 70: 859-875.

Gonzalez JE, Marketon MM (2003) Quorum sensing in nitrogen-fixing Rhizobia. Microbiol Mol Biol Rev 67: 574592.

Gotschilich A, Huber B, Geisenberger O, Togl A, Steidle A, Riedel K, Hill P, Tummler B, Vandamme P, Middleton B, Camara M, Williams P, Hardman A, Eberl L (2001) Synthesis of multiple $N$-acylhomoserine lactones is wide-spread among members of Burkholderia cepacia complex. Syst Appl Microbiol 24: 1-14.

Gray KM (1997) Intercellular communication and group behavior in bacteria. Trends Microbiol 5: 184-188.

Hanzelka BL, Greenberg EP (1995) Quorum sensing in Vibrio fischeri: evidence that $S$-adenosylmethionine is the amino acid substrate for autoinducer synthesis. J Bacteriol 178: 5291-5294.

de Haan E, Dekker-Nooren TCEM, van den Bovenkamp GW, Speksnijder AGCL, van der Zouwen PS, van der Wolf JM (2008) Pectobacterium carotovorum subsp. carotovorum can cause potato blackleg in temperate climates. Eur J Plant Pathol 122: 561-569.

Henke JM, Bassler BL (2004) Bacterial social engagements. Trends Cell Biology 14: 648-656.

Hentzer M, Wu H, Andersen JB, Riedel K, Rasmussen TB, Bagge N, Kumar N, Schembri MA, Song Z, Kristoffersen P, Manefield M, Costerton JW, Molin S, Eberl L, Steinberg P, Kjelleberg S, Høiby N, Givskov M (2003) Attenuation of Pseudomonas aeruginosa virulence by quorum sensing inhibitors. EMBO J 22: 3803-3815.

Hoang HH, Becker A, Gonzalez JE (2004) The LuxR homolog ExpR, in combination with the Sin quorum sensing system, plays a central role in Sinorhizobium meliloti gene expression. J Bacteriol 186: 5460-5472.

Huang JJ, Han JI, Zhang LH, Leadbetter JR (2003) Utilization of acyl-homoserine lactone quorum signals for growth by a soil pseudomonad and Pseudomonas aeruginosa PAO1. Appl Environ Microbiol 69: 5941-5949.

Huang JJ, Petersen A, Whiteley M, Leadbetter JR (2006) Identification of QuiP, the product of gene PA1032, as the second acyl-homoserine lactone acylase of Pseudomonas aeruginosa PAO1. Appl Environ Microbiol 72: 1190-1197.

Jafra S, Jalink $H$, van der Schoor $R$, van der Wolf JM (2006a) Pectobacterium carotovorum subsp. carotovorum strains show diversity in production of and response to $N$-acyl homoserine lactones. J Phytopathol 154: 729-739.

Jafra S, Przysowa J, Czajkowski R, Michta A, Garbeva P, van der Wolf JM (2006b) Detection and characterization of $\mathrm{N}$-acyl homoserine lactone-degrading bacteria from the potato rhizosphere. Can J Microbiol 52: 1006-1015.

Jones S, Yu B, Bainton NJ, Birdsall M, Bycroft BW, Chhabra SR, Cox AJ, Golby P, Reeves PJ, Stephens S et al. (1993) The lux autoinducer regulates the production of exoenzyme virulence determinants in Erwinia carotovora and Pseudomonas aeruginosa. EMBO J 12: 2477-2482.

Kaiser D, Losick R (1993) How and why bacteria talk to each other. Cell 73: 873-885.

Kang BR, Lee JH, Ko SJ, Lee YH, Cha JS, Cho BH, Kim YC (2004) Degradation of acyl-homoserine lactone molecules by Acinetobacter sp. strain C1010. Can J Microbiol 50: 935-941.

Kaplan HB, Greenberg EP (1985) Diffusion of autoinducer is involved in regulation of the Vibrio fischeri luminescence system. J Bacteriol 163: 1210-1214.

Kaufmann GF, Sartorio R, Lee SH, Rogers CJ, Meijler MM, Moss JA, Clapham B, Brogan AP, Dickerson TJ, Janda KD (2005) Revisiting quorum sensing: Discovery of additional chemical and biological functions for 3-oxo- $N$ acylhomoserine lactones. Proc Natl Acad Sci USA 102: 309-314.

Khan SR, Farrand SK (2009) The BlcC (AttM) lactonase of Agrobacterium tumefaciens does not quench the quorumsensing system that regulates $\mathrm{Ti}$ plasmid conjugative transfer. J Bacteriol 191: 1320-1329.

Kim Y, Yoon K, Khang Y, Turley S, Hol WG (2000) The 2.0 $\AA$ crystal structure of cephalosporin acylase. Structure 8: 1059-1068.

Kim MH, Choi WC, Kang HO, Lee JS, Kang BS, Kim KJ, Derewenda ZS, Oh TK, Lee CH, Lee JK (2005) The molecular structure and catalytic mechanism of a quorumquenching $N$-acyl-L-homoserine lactone hydrolase. Proc Natl Acad Sci USA 102: 17606-17611.

de Kievit TR, Iglewski BH (2000) Bacterial quorum sensing in pathogenic relationships. Infect Immun 68: 48394849.

Kleerebezem M, Quadri LE, Kuipers OP, de Vos WM (1997) Quorum sensing by peptide pheromones and 
two-component signal-transduction systems in Grampositive bacteria. Mol Microbiol 24: 895-904.

Knutsen E, Ween O, Havarstein LS (2004) Two separate quorum-sensing systems upregulate transcription of the same $\mathrm{ABC}$ transporter in Streptococcus pneumoniae. J Bacteriol 186: 3078-3085.

Leadbetter JR (2001) Plant microbiology. Quieting the raucous crowd. Nature 411: 748-749.

Leadbetter JR, Greenberg EP (2000) Metabolism of acyl-homoserine lactone quorum-sensing signals by Variovorax paradoxus. J Bacteriol 182: 6921-6926.

Lee SJ, Park SY, Lee JJ, Yum DY, Koo BT, Lee JK (2002) Genes encoding the $N$-acyl homoserine lactone-degrading enzyme are widespread in many subspecies of Bacillus thuringiensis. Appl Environ Microbiol 68: 39193924.

Lin $\mathrm{YH}, \mathrm{Xu} \mathrm{JL}, \mathrm{Hu} \mathrm{J}$, Wang LH, Ong SL, Leadbetter JR, Zhang LH (2003) Acyl-homoserine lactone acylase from Ralstonia strain XJ12B represents a novel and potent class of quorum-quenching enzymes. Mol Microbiol 47: 849-860.

Liu D, Lepore BW, Petsko GA, Thomas PW, Stone EM, Fast W, Ringe D (2005) Three-dimensional structure of the quorum-quenching $N$-acyl homoserine lactone hydrolase from Bacillus thuringiensis. Proc Natl Acad Sci USA 102: 11882-11887.

Loh J, Pierson EA, Pierson LS 3rd, Stacey G, Chatterjee A (2002) Quorum sensing in plant-associated bacteria. Curr Opin Plant Biol 5: 285-290.

Ma B, Hibbing ME, Kim HS, Reedy RM, Yedidia I, Breuer J, Breuer J, Glasner JD, Perna NT, Kelman A, Charkowski AO (2007) The host range and molecular phylogenies of the soft rot enterobacterial genera Pectobacterium and Dickeya. Phytopathology 97: 1150-1163.

Maë A, Montesano M, Koiv V, Palva ET (2001) Transgenic plants producing the bacterial pheromone $\mathrm{N}$-acyl-homoserine lactone exhibit enhanced resistance to the bacterial phytopathogen Erwinia carotovora. Mol Plant Microbe Interact 14: 1035-1042.

Manefield M, de Nys R, Kumar N, Read R, Givskov M, Steinberg P, Kjelleberg S (1999) Evidence that halogenated furanones from Delisea pulchra inhibit acylated homoserine lactone (AHL)-mediated gene expression by displacing the AHL signal from its receptor protein. Microbiology 145: 283-291.

Manefield M, Welch M, Givskov M, Salmond GPC, Kjelleberg S (2001) Halogenated furanones from red alga, Delisea pulchra, inhibit carbapenem antibiotic synthesis and exoenzyme virulence factor production in the phytopathogen Erwinia carotovora. FEMS Micorobiol Lett 205: 131-138.

Marketon MM, Gonzalez JE (2002) Identification of two quorum-sensing systems in Sinorhizobium meliloti. J Bacteriol 184: 3466-3475.

Marketon MM, Gronquist MR, Eberhard A, Gonzalez JE (2002) Characterization of the Sinorhizobium meliloti $\operatorname{sinR} / \sin I$ locus and the production of novel $\mathrm{N}$-acyl homoserine lactones. J Bacteriol 184: 5686-5695.

Mayville P, Ji G, Beavis R, Yang H, Goger M, Novick RP, Muir TW (1999) Structure-activity analysis of synthetic autoinducing thiolactone peptides from Staphylococcus aureus responsible for virulence. Proc Natl Acad Sci USA 96: 1218-1223.

Milton DL, Chalker VJ, Kirke D, Hardman A, Camara M, Williams P (2001) The LuxM homologue VanM from Vibrio anguillarum directs the synthesis of $N$-(3-hydroxyhexanoyl) homoserine lactone and $N$-hexanoylhomoserine lactone. J Bacteriol 183: 3537-3547.
Milton DL, Hardman A, Camara M, Chhabra SR, Bycroft BW, Stewart GS, Williams P (1997) Quorum sensing in Vibrio anguillarum: characterization of the vanI/vanR locus and identification of the autoinducer $N$-(3-oxodecanoyl)-L-homoserine lactone. J Bacteriol 179: 30043012.

Molina L, Rezzenico F, Defago G, Duffy B (2005) Autoinduction in Erwinia amylovora: evidence of an acylhomoserine lactone signal in the fire blight pathogen. J Bacteriol 187: 3206-3213.

Molina L, Constantinescu F, Michel L, Reimmann C, Duffy B, Défago G (2003) Degradation of pathogen quorumsensing molecules by soil bacteria: a preventive and curative biological control mechanism. FEMS Microbiol Ecol 45: 71-81.

Muh U, Schuster M, Heim R, Singh A, Olson ER, Greenberg EP (2006) Novel Pseudomonas aeruginosa quorumsensing inhibitors identified in an ultra-high-throughput screen. Antimicrob Agents Chemother 50: 3674-3679.

Nealson KH, Platt T, Hastings JW (1970) Cellular control of the synthesis and activity of the bacterial luminescent system. J Bacteriol 104: 313-322.

Oinonen C, Rouvinen J (2000) Structural comparison of Ntn-hydrolases. Protein Sci 9: 2329-2337.

Ozer EA, Pezzulo A, Shih DM, Chun C, Furlong C, Lusis AJ, Greenberg EP, Zabner J (2005) Human and murine paraoxonase 1 are host modulators of Pseudomonas aeruginosa quorum-sensing. FEMS Microbiol Lett 253: 29-37.

Paggi RA, Martone CB, Fuqua C, De Castro RE (2003) Detection of quorum sensing signals in the haloalkaliphilic archaeon Natronococcus occultus. FEMS Microbiol Lett 221: 49-52.

Park SJ, Park SY, RyuCM, Park SH, Lee JK (2008) The role of AiiA, a quorum-quenching enzyme from Bacillus thuringiensis, on the rhizosphere competence. J Microbiol Biotechnol 18: 1518-1521.

Park SY, Kang HO, Jang HS, Lee JK, Koo BT, Yum DY (2005) Identification of extracellular N-acylhomoserine lactone acylase from a Streptomyces sp. and its application to quorum quenching. Appl Environ Microbiol 71: 2632-2641.

Park SY, Hwang BJ, Shin MH, Kim JA, Kim HK, Lee JK (2006) N-acylhomoserine lactonase-producing Rhodococcus spp. with different AHL-degrading activities. FEMS Microbiol Lett 261: 102-108.

Park SY, Lee SJ, Oh TK, Oh JW, Koo BT, Yum DY, Lee JK (2003) AhlD, an N-acylhomoserine lactonase in Arthrobacter sp., and predicted homologues in other bacteria. Microbiology 149: 1541-1550.

Pearson JP, Pesci EC, Iglewski BH (1997) Roles of Pseudomonas aeruginosa las and rhl quorum-sensing systems in control of elastase and rhamnolipid biosynthesis genes. J Bacteriol 179: 5756-5767.

Pearson JP, Van Delden C, Iglewski BH (1999) Active efflux and diffusion are involved in transport of Pseudomonas aeruginosa cell-to-cell signals. J Bacteriol 181: 1203-1210.

Pérombelon MCM (2002) Potato diseases caused by soft rot erwinias: An overview of pathogenesis. Plant Pathol 51: 1-12.

Pérombelon MCM, Kelman A (1980) Ecology of the soft rot erwinias. Annu Rev Phytopathol 18: 361-387.

Pirhonen M, Flego D, Heikinheimo R, Palva ET (1993) A small diffusible signal molecule is responsible for the global control of virulence and exoenzyme production in the plant pathogen Erwinia carotovora. EMBO J 12: 2467-2476. 
Podbielski A, Bernd Kreikemeyer B (2004) Cell density-dependent regulation: basic principles and effects on the virulence of Gram-positive cocci. Int J Infect Diseases 8: 81-95.

Rasmussen TB, Bjarnsholt T, Skindersoe ME, Hentzer M, Kristoffersen P, Kote M, Nielsen J, Eberl L, Givskov M. (2005) Screening for quorum sensing inhibitors (QSI) by use of a novel genetic system, the QSI selector. J Bacteriol 187: 1799-1814.

Reading NC, Sperandio V (2006) Quorum sensing: the many languages of bacteria. FEMS Microbiol Lett 254: $1-11$.

Reverchon S, Chantegrel B, Deshayes C., Doutheau A, Cotte-Pattat N (2002) New synthetic analogues of $N$ acyl homoserine lactones as agonists or antagonists of transcriptional regulatiors involved in bacterial quorum sensing. Bioorg Med Chem Lett 12: 1153-1157.

Reimmann C, Beyeler M, Latifi M, Winteler H, Foglino M, Lazdunski A, Haas D (1997) The global activator GacA of Pseudomonas aeruginosa PAO positively controls the production of the autoinducer $N$-butyryl-homoserine lactone and the formation of the virulence factors pyocyanin, cyanide, and lipase. Mol Microbiol 24: 309-319.

Reimmann C, Ginet N, Michel L, Keel C, Michaux P, Krishnapillai V, Zala M, Heurlier K, Triandafillu K, Harms H, Defago G, Haas D (2002) Genetically programmed autoinducer destruction reduces virulence gene expression and swarming motility in Pseudomonas aeruginosa PAO1. Microbiology 148: 923-932.

Rivas M, Seeger M, Jedlicki E, Holmes DS (2007) Second acyl-homoserine lactone producing system in the extreme acidophile Acidithiobacillus ferrooxidans. Appl Environ Microbiol 73: 3225-3231.

Romero M, Diggle SP, Heeb S, Camara M, Otero A (2008) Quorum quenching activity in Anabaena sp. PCC7120: identification of AiiC, a novel AHL-acylase. FEMS Microb Lett 280: 73-80.

Rosemeyeer V, Michiels J, Verreth C, Vanderlryden J (1998) luxI and luxR-homologous genes of Rhizobium etli CNPAF512 contribute to synthesis of autoinducer molecules and nodulation of Phaseolus vulgaris. J Bacteriol 180: 815-821.

Sio CF, Otten LG, Cool RH, Diggle SP, Braun PG, Bos R, Daykin M, Camara M, Williams P, Quax WJ (2006) Quorum quenching by an $\mathrm{N}$-acyl-homoserine lactone acylase from Pseudomonas aeruginosa PAO1. Infect Immun 74: 1673-1682.

Steidle A, Sigl K, Schuhegger R, Ihring A, Schmid M, Gantner S, Stoffels M, Riedel K, Givskov M, Hartmann A, Langebartels C, Eberl L (2001) Visualization of N-acylhomoserine lactone-mediated cell-cell communication between bacteria colonizing the tomato rhizosphere. Appl Environ Microbiol 67: 5761-5770.

Swift S, Stewart GS, Williams P ( 1996) The inner workings of a quorum sensing signal generator. Trends Microbiol 4: $463-466$.

Swift S, Winson MK, Chan PF, Bainton NJ, Birdsall M, Reeves PJ, Rees CED, Chhabra SR, Hill PJ, Throup JP, Bycroft BW, Salmond GPC, Williams P, Stewart GSAB (1993) A novel strategy for the isolation of luxI homologues: evidence for the widespread distribution of a LuxR:LuxI superfamily in enteric bacteria. Mol Microbiol 10: 511-520.

Teiber JF, Draganov DI, La Du BN (2003) Lactonase and lactonizing activities of human serum paraoxonase (PON1) and rabbit serum PON3. Biochem Pharmacol 66: 887-896.

Teplitski M, Robinson JB, Bauer WD (2000) Plants secrete substances that mimic bacterial $N$-acyl homoserine lac- tone signal activity and affect population density-dependent behaviours in associated bacteria. Mol Plant Microbe Interact 13: 637-648.

Toth IK, Newton JA, Hyman LJ, Lees AK, Daykin M, Ortori C, Williams P, Fray RG (2004) Potato plants genetically modified to produce $N$-acylhomoserine lactones increase susceptibility to soft rot Erwiniae. Mol Plant Microbe Interact 17: 880-887.

Turovskiy Y, Kashtanov D, Paskhover B, Chikindas ML (2007) Quorum sensing: Fact, fiction, and everything in between. Adv Appl Microbiol 62: 191-234.

Ulrich RL (2004) Quorum quenching enzymatic disruption of $\mathrm{N}$-acylhomoseirne lactone-mediated bacterial communication in Burkholderia thailandensis. Appl Environ Microbiol 70: 6173-6180.

Uroz S, D'Angelo-Picard C, Carlier A, Elasri M, Sicot C, Petit A, Oger P, Faure D, Dessaux Y (2003) Novel bacteria degrading $\mathrm{N}$-acylhomoserine lactones and their use as quenchers of quorum-sensing-regulated functions of plant-pathogenic bacteria. Microbiology 149: 1981-1989.

Uroz S, Chhabra SR, Camara M, Williams P, Oger P, Dessaux Y (2005) N-Acylhomoserine lactone quorum-sensing molecules are modified and degraded by Rhodococcus erythropolis W2 by both amidolytic and novel oxidoreductase activities. Microbiology 151: 3313-3322.

Uroz S, Oger PM, Chhabra SR, Camara M, Williams P, Dessaux Y (2006) N-acyl homoserine lactones are degraded via an amidolytic activity in Comamonas sp. strain D1. Arch Microbiol 187: 249-256.

Uroz S, Oger PM, Chapelle E, Adeline MT, Fauer D, Dessaux Y (2008) A Rhodococcus qsd-A-encoded enzyme defines a novel class of large-spectrum quorum quenching lactonases. Appl Environ Micobiol 74: 1357-1366.

Wang LH, Weng LX, Dong YH, Zhang LH (2004) Specificity and enzyme kinetics of the quorum-quenching $N$ acyl homoserine lactone lactonase (AHL lactonase). J Biol Chem 279: 13645-13651.

Whistler CA, Pierson III LS (2003) Repression of phenazine antibiotic production in Pseudomonas aureofaciens strain 30-84 by RpeA. J Bacteriol 185: 3718-3725.

Whitehead NA, Barnard AM, Slater H, Simpson NJ, Salmond GP (2001) Quorum-sensing in Gram-negative bacteria. FEMS Microbiol Rev 25: 365-404.

Whitehead NA, Byers JT, Commander P, Corbett MJ, Coulthurst SJ, Everson L, Harris AK, Pemberton CL, Simpson NJ, Slater H, Smith DS, Welch M, Williamson N, Salmond GP (2002) The regulation of virulence in phytopathogenic Erwinia species: quorum sensing, antibiotics and ecological considerations. Antonie Van Leeuwenhoek 81: 223-231.

Williams P (2007) Quorum sensing, communication and cross-kingdom signaling in the bacterial world. Microbiology 153: 3923-3938.

Williams P, Winzer K, Chan W, Camara M (2007) Look who's talking: communication and quorum sensing in the bacterial world. Philos Trans $R$ Soc London B Biol Sci 362: 1119-1134.

Wisniewski-Dye F, Jones J, Chhabra SR, Downie JA (2002) railR genes are part of a quorum-sensing network controlled by cinI and cinR in Rhizobium leguminosarum. J Bacteriol 184: 1597-1606.

Wu H, Song Z, Hentzer M, Andersen JB, Molin S, Givskov M, Høiby N (2004) Synthetic furanones inhibit quorum-sensing and enhance bacterial clearance in Pseudomonas aeruginosa lung infection in mice. J Antimicrob Chemother 53: 1054-1061.

Yang WW, Han JI, Leadbetter JR (2006) Utilization of homoserine lactone as a sole source of carbon and en- 
ergy by soil Arthrobacter and Burkholderia species. Arch Microbiol 185: 47-54.

Yang F, Wang LH, Wang J, Dong YH, Hu JY, Zhang LH (2005) Quorum quenching activity is widly conserved in the sera of mammalian species. FEBS Lett. 579: 37133717.

Yoon JH, Lee JK, Jung SY, Kim JA, Kim HK, Oh TK (2006) Nocardioides kongjuensis sp. nov., an N-acylhomoserine lactone-degrading bacterium. Int J Syst Evol Microbiol 56: 1783-1787.

Zhang LH (2003) Quorum quenching and proactive host defense. Trends Plant Sci 8: 238-244.
Zhang LH, Murphy PJ, Kerr A, Tate ME (1993) Agrobacterium conjugation and gene regulation by $N$-acyl-L-homoserine lactones. Nature 362: 446-447.

Zhang HB, Wang C, Zhang LH (2004) The quormone degradation system of Agrobacterium tumefaciens is regulated by starvation signal and stress alarmone (p)ppGpp. Mol Microbiol 52: 1389-1401.

Zhang HB, Wang LH, Zhang LH (2002) Genetic control of quorum-sensing signal turnover in Agrobacterium tumefaciens. Proc Natl Acad Sci USA 99: 4638-4643. 